\title{
Biogeography and phylogeny of Chondrilla species (Demospongiae) in Australia
}

\author{
Kayley M. Usher ${ }^{1, *}$, David C. Sutton ${ }^{1}$, Simon Toze ${ }^{2}$, John Kuo ${ }^{3}$, Jane Fromont ${ }^{4}$ \\ ${ }^{1}$ The Department of Microbiology, University of Western Australia, 35 Stirling Highway, Crawley, \\ 6009 Western Australia, Australia \\ ${ }^{2}$ CSIRO Land and Water, Underwood Avenue, Floreat, 6014 Western Australia, Australia \\ ${ }^{3}$ The Centre for Microscopy and Microanalysis, University of Western Australia, 35 Stirling Highway, Crawley, \\ 6009 Western Australia, Australia \\ ${ }^{4}$ Western Australian Museum, Perth Cultural Centre, Perth, 6000 Western Australia, Australia
}

\begin{abstract}
The biogeography and phylogeny of Chondrilla (Porifera, Demospongiae) species in Australia is poorly understood. Until the present study was carried out, 4 Chondrilla species were thought to occur in the waters of Australia and its territories: C. australiensis, C. secunda, C. mixta and $C$. nucula. However, the type specimen of the latter comes from the Adriatic Sea, and it has always been uncertain whether this species is present in Australia. The difficulty in determining the number of species of Chondrilla and their biogeography is largely due to the paucity of phenotypic characters that are normally used for identification. To clarify the diversity and distribution of sponges in this genus in Australia, DNA sequence analysis was applied to samples of Chondrilla from around Australia and compared to C. nucula from the Mediterranean. Classical taxonomic techniques were used to confirm the molecular results. Evidence was found for 3 species of Chondrilla in the temperate southern oceans of Australia with one, C. australiensis, also extending into tropical waters. All 3 species were distinct from C. nucula, which was not found in Australian waters in this study. The distribution of $C$. australiensis suggests that larvae and/or fragments of this sponge are able to disperse across very large distances around the coastline of Australia. Species identification based on direct sequencing of the D2 region in the 28S rDNA and ITS1-5.8S-ITS2 region was in agreement with results using classical taxonomic techniques.
\end{abstract}

KEY WORDS: Chondrilla · Porifera · Biogeography · Phylogeny · Molecular analysis · Classical taxonomy

Resale or republication not permitted without written consent of the publisher

\section{INTRODUCTION}

Although sponges in the genus Chondrilla (class Demospongiae, order Chondrosida, family Chondrillidae, sub-class Tetractinomorpha) are an important and abundant component of reefs in both tropical and temperate oceans of the world, the exact number of Chondrilla species remains uncertain. The taxonomy of this genus is problematic due to the relative simplicity of the skeleton and the presence of few spicule types, with species largely distinguished by the dimensions and structure of the single type of spicule they contain, the aster. This lack of defining morphological characters has caused confusion, with many of the 13 species reported in the Zoological Catalogue of Australia now regarded as synonyms (Hooper \& Wiedenmayer 1994). Based on classical taxonomic techniques, 4 species of Chondrilla are currently recognized from Australian waters: C. australiensis, C. nucula and C. secunda, with the fourth, C. mixta, recorded from Christmas Island, an Australian territory. The distribution of these species in Australia has not been investigated, but both C. australiensis and C. nucula have been recorded from the Indian and Pacific oceans, and also in geo- 
graphically distant areas such as the Red Sea and the Mediterranean Sea, respectively. However, given the low dispersal ability of the gametes and larvae of sponges (Watanabe \& Masuda 1990, Lazoski et al. 2001), it seems unlikely that these species are cosmopolitan.

The supposed cosmopolitan nature of Chondrilla species has been brought into question by the only study to date using molecular techniques to investigate their distribution. Klautau et al. (1999) used allozyme electrophoresis to analyze sponges thought to be $C$. nucula from the Caribbean, southwest Atlantic and Mediterranean Sea and found that they comprised a complex of 5 species, with $C$. nucula occurring only in the Mediterranean. The lack of defining morphological features in this genus may have led to an underestimation of the number and identity of Chondrilla species in Australia.

Sponge taxonomy is a challenging area, as sponges are morphologically simple and plastic, and even their higher-level systematics have not been adequately clarified (Lévi 1979, Solé-Cava et al. 1992). Classical taxonomy has traditionally been based on skeletal structure and spicule type and dimensions, but the usefulness of spicule morphometric analysis has been questioned, as spicule size can vary within species and is influenced by environmental factors (Jones 1984, Hooper et al. 1991, Bavestrello et al. 1993). There is thus a need to clarify the usefulness of these morphological characters and to find additional techniques that would assist in distinguishing between closely related sponge species.

As noted above, allozyme electrophoresis has been applied to the problem of distinguishing between sponge species, and is the molecular technique most widely used to study sponge population genetics. Many of these studies have revealed discrepancies between allozyme and spicule morphometric analysis (Solé-Cava \& Thorpe 1986, Solé-Cava et al. 1992, Muricy et al. 1996, Klautau et al. 1999), and the authors have concluded that spicules alone are not reliable characters to distinguish the species investigated. However, this is not always the case, with good correlations found between these methods for some species (Sarà et al. 1993). The wide range of interspecific gene identity values obtained between sponge species complicates the use and interpretation of allozyme analysis. In a review of papers using this technique, SoléCava \& Boury-Esnault (1999) classified 3 categories of results: (1) genera where interspecies comparisons give similar levels of gene identity to those found among other invertebrates; (2) genera where some pair-wise species comparisons give very low identity values, while other species in the genus have identity values comparable to those found among species in other taxa; (3) genera where interspecies comparisons consistently give extremely low identity values. These results make it difficult to set a threshold value for conspecific gene identity in sponges. This is further compounded by the lack of knowledge of the reproductive ecology of most sponge species, which would allow an understanding of their dispersal ability and consequent distribution potential.

While there have been a number of interspecific and intraspecific studies of sponges using allozyme electrophoresis, there have been very few DNA sequencing analyses undertaken to distinguish sponges at the species level. It appears that several regions commonly used for phylogenetic analysis of other animal genera are not sufficiently divergent in sponges to be useful. For example, mitochondrial DNA sequences are often used to distinguish eukaryote species, but do not have enough variation in Porifera (van Oppen et al. 2002, Wörheide et al. 2002) to be used at the species level. Sponges also have much less variation in the $18 \mathrm{~S}$ ribosomal DNA (rDNA) than other eukaryotes (McInerney et al. 1999). However, restriction fragment length polymorphisms of the internal transcribed spacers (ITS) have been successfully used by several sponge researchers to distinguish closely related sponge species (Wörheide 1998, Boyce 1999), and Wörheide et al. $(2000,2002)$ used sequencing analysis of the ITS15.8S-ITS2 region to investigate phylogeographical relationships within sponge species on the Great Barrier Reef.

The D2 region, one of the most variable domains of the 28S rDNA in eukaryotes (Hassouna et al. 1984), has been used to establish phylogenetic relationships between closely related species of protists (Baroin et al. 1988), but has not been applied for this purpose in sponges. The $28 \mathrm{~S}$ rDNA has also been successfully used to analyze sponge phylogeny at the genus level (Chombard et al. 1998, McInerney et al. 1999, Borchiellini et al. 2000), and the high degree of sequence divergence found in the D2 domain suggests that this region may be useful for species-level phylogenetics.

The aim of the present study was to establish the number of Chondrilla species in the oceans of Australia and determine their biogeography. To accomplish this, specimens of Chondrilla were sampled around Australia, and the D2 and ITS1 and ITS2 regions of the ribosomal DNA sequenced. The sequences were compared to those of $C$. nucula from the Mediterranean, Ligurian Sea and Bermuda to provide evidence on the occurrence or otherwise of $C$. nucula in Australia. In addition, morphological and spicule characteristics were compared with the molecular analysis to establish congruence, or lack of it, between the 2 approaches. 


\section{MATERIALS AND METHODS}

Samples of Chondrilla were collected using SCUBA from depths up to $25 \mathrm{~m}$. In Australia these were collected from the following sites: Cape le Grande; Esperance jetty; King George Sound, Albany; Two People's Bay; Busselton jetty; South Mole, Fremantle;
Marmion; Mid Reef, Houtman Abrolhos Islands; Exmouth; Dampier; North Stradbroke Island; Moreton Bay; Bateau Bay; Western River Cove, Kangaroo Island; and Queenscliff (Table 1, Fig. 1). Samples of C. nucula were collected from the Mediterranean Sea, Marseille, France; and the Ligurian Sea, Portofino, Italy (Table 1). Chondrilla specimens were

Table 1. Sample information for Chondrilla species used in this study. C2D2: number of base pairs (bp) sequenced from the 28S rDNA region amplified with this primer pair. ITS: number of base pairs sequenced of the ITS1 and ITS2 region of rDNA. Abbreviations: $C$. aust = Chondrilla australiensis, C. $\operatorname{sp} 2=$ Chondrilla sp. 2, C. sp $3=$ Chondrilla sp. 3, C. nuC =Chondrilla nucula; C. sp $4=$ Chondrilla sp. 4 ; SA = South Australia, WA = Western Australia, Vic = Victoria, NSW = New South Wales, NT = Northern Territory, Qld = Queensland; BMNH = British Museum of Natural History, WAM = Western Australian Museum, ZMH = Zoologische Museum Hamburg, NTM = Museum and Art Gallery of the Northern Territory, AM = Australian Museum

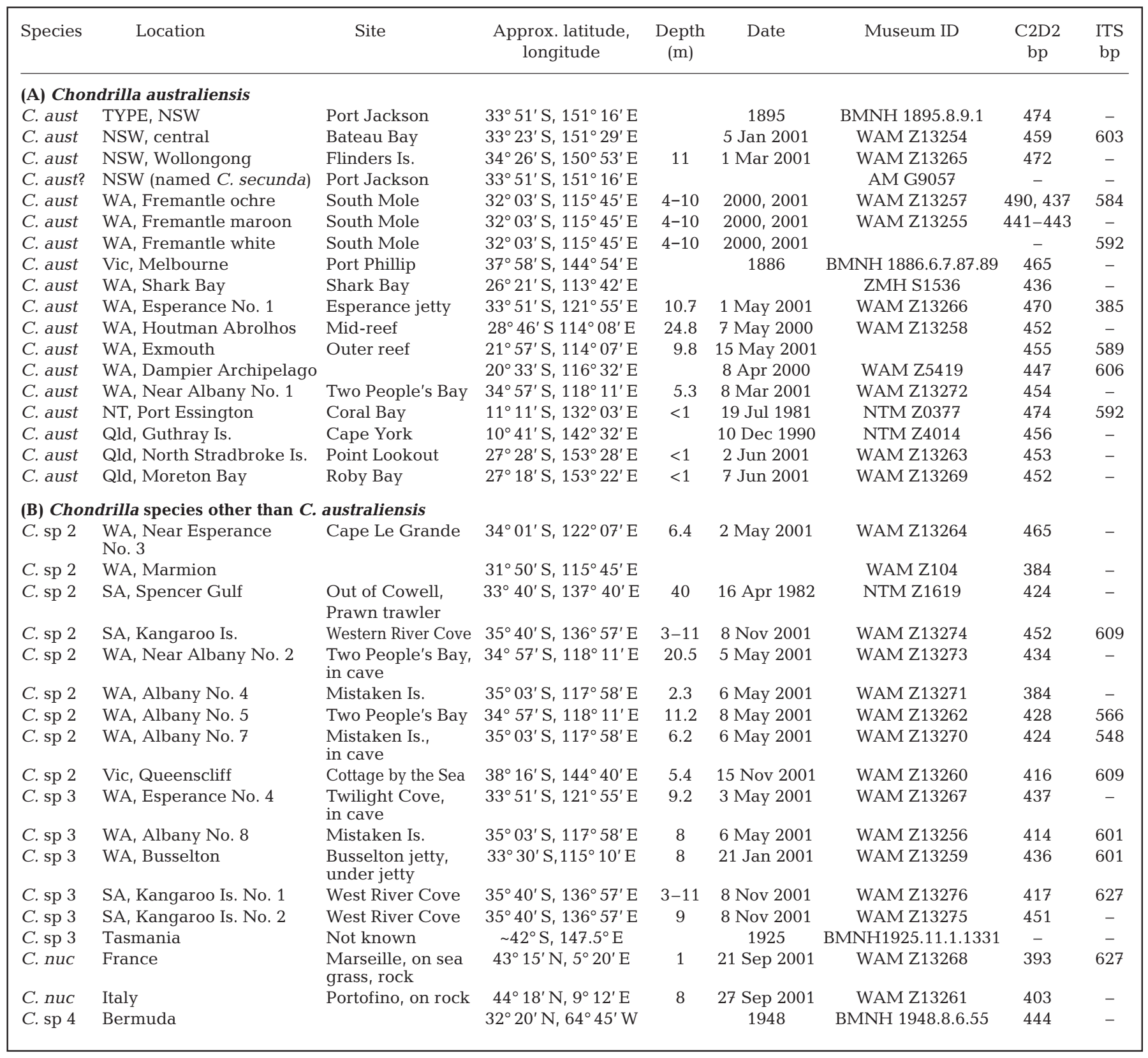


deposited in the Western Australian Museum (Table 1).

Sponge specimens were kept shaded in seawater until preserved by 1 or more of the following methods, depending on the availability of freezers after collection: (1) Freezing at $-20^{\circ} \mathrm{C}$, then transferring to $-80^{\circ} \mathrm{C}$; as soon as possible; (2) placing approximately $1 \mathrm{~cm}^{2}$ pieces into $20 \%$ dimethyl sulphoxide (DMSO) (250 mM Na 2 EDTA pH 8.0, $20 \%$ DMSO saturated with $\mathrm{NaCl}, \mathrm{pH}$ adjusted to 7.5); (3) placing in $80 \% \mathrm{EtOH}$.

EtOH preserved samples of Chondrilla were also obtained from the Natural History Museum of London (NHM), including the type specimen of $C$. australiensis from New South Wales (Port Jackson), and Chondrilla samples from Victoria (Port Phillip Bay), Tasmania and Bermuda. In addition, the Museum and Art Gallery of the Northern Territory provided samples from the Northern Territory (Port Essington) and South Australia (Spencer Gulf).

Extraction of DNA. Approximately $5 \mathrm{~mm}^{3}$ of sponge tissue was excised and chopped finely with a sterile razor, and EtOH preserved samples were then airdried for 1 to $2 \mathrm{~h}$. Foreign eukaryotic organisms were removed if found in the sponge tissue. Samples were then placed in $2 \mathrm{ml}$ Eppendorf tubes, and $200 \mu \mathrm{l}$ of

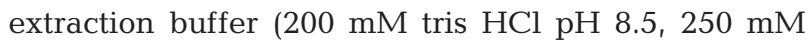
$\mathrm{NaCl}, 25 \mathrm{mM} \mathrm{Na}_{2}$ EDTA, $0.5 \%$ SDS) added. The tissue was crushed with the blunt end of a sterile plastic loop and then freeze-thawed at $-20^{\circ} \mathrm{C} /$ room temperature 3 times to disrupt cell membranes. The supernatant was transferred to a clean Eppendorf tube and centrifuged at $27000 \times g$ for $1 \mathrm{~min}$ to pellet cell debris. The

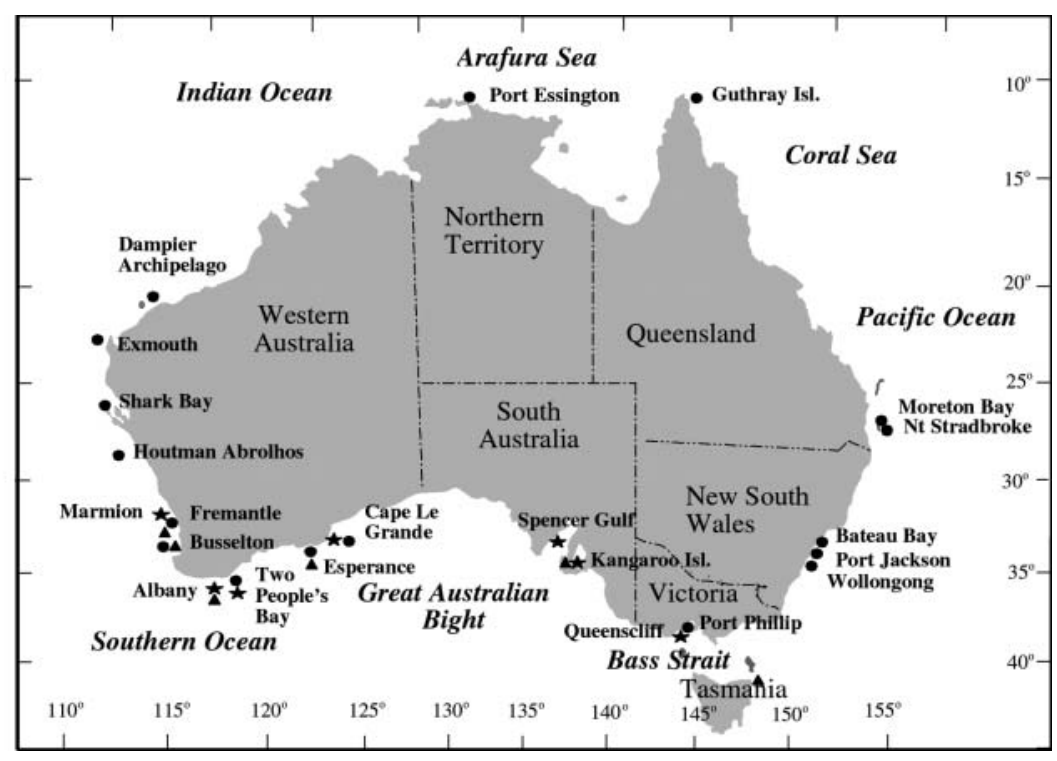

Fig. 1. Map of Australia showing collection sites and distribution of the 3 Chondrilla species found in this study. Circles: C. australiensis; stars: Chondrilla sp. 2; triangles: Chondrilla sp. 3 supernatant was removed and purified with a BresaSpin PCR clean-up kit (Bresatec, Australia) as per the manufacturer's protocol, and used in PCR analysis.

Some sponge samples (Chondrilla nucula from France and Italy, Chondrilla sp. 2 from Victoria, C. australiensis from New South Wales, Abrolhos and Fremantle) were amplified directly from tissue excised from the sponge by placing the tissue directly into the $\mathrm{PCR}$ reaction (see below).

PCR reactions. PCR reactions were carried out with a final volume of $25 \mu \mathrm{l}$. The PCR mix contained $2 \mathrm{U}$ Finnzyme DNA polymerase (Finnzyme), $1 \times$ Finnzyme buffer, $1.5 \mathrm{mM} \mathrm{MgCl}_{2}, 200 \mu \mathrm{M}$ of each dNTP, and 15 pmol of each oligonucleotide primer. 5\% DMSO was added to PCR reactions using the C2 D2 primer set. 1.25 and $3.25 \mu$ of cleaned DNA of each sample was added to separate $25 \mu \mathrm{l} \mathrm{PCR} \mathrm{reactions.} \mathrm{Otherwise,}$ $1 \mathrm{~mm}^{3}$ of sponge sample was placed directly into $25 \mu \mathrm{l}$ of PCR mix. PCR reactions were run on a PTC-200 Peltier Thermal Cycler.

The C2 universal forward primer (5'- GAA AAG AAC TTT GRA RAG AGA GT -3') and D2 universal reverse primer (5' - TCC GTG TTT CAA GAC GGG -3') (Chombard et al. 1998) were used, priming approximately $475 \mathrm{bp}$ of the $5^{\prime}$ end of the $28 \mathrm{~S}$ rDNA. An initial cycle of $95^{\circ} \mathrm{C}$ for $1 \mathrm{~min}$, then 35 cycles of $94^{\circ} \mathrm{C}$ for $30 \mathrm{~s}$, $54^{\circ} \mathrm{C}$ for $45 \mathrm{~s}$, and $72^{\circ} \mathrm{C}$ for 1 min was used with this primer set. This was followed by 1 cycle of $72^{\circ} \mathrm{C}$ for $5 \mathrm{~min}$, with a hold at $4^{\circ} \mathrm{C}$.

The ITS1 universal forward primer, $5^{\prime}$ - TCC GTA TGG TGA ACC TGC GG -3', and ITS4 universal reverse primer, $5^{\prime}-$ TCC TCC GCT TAT TGA TAT GC -3' (Wang \& White 1997), were also applied. The ITS primers begin at the end of the 18S rDNA and amplify 665 bp of the ITS1, 5.8S rDNA and ITS2 region, ending at the beginning of the 28S rDNA. An initial cycle of $95^{\circ} \mathrm{C}$ for $2 \mathrm{~min}$, then 35 cycles of $94^{\circ} \mathrm{C}$ for $30 \mathrm{~s}$, $48^{\circ} \mathrm{C}$ for $45 \mathrm{~s}$, and $72^{\circ} \mathrm{C}$ for 1 min was used. This was followed by 1 cycle of $72^{\circ} \mathrm{C}$ for $5 \mathrm{~min}$, with a hold at $4^{\circ} \mathrm{C}$.

Sequencing. PCR products were purified with a Bresaspin PCR Cleanup kit (Bresatec, Australia) according to the manufacturer's protocol. Sequencing reactions were performed using BigDye Terminator Mix version 3 (Applied Biosystems, USA), as per the manufacturer's instructions, with 3.2 pmol of primer, except the final volume was $10 \mu \mathrm{l}$ and contained $4 \mu \mathrm{l}$ of BigDye Terminator mix. Direct sequencing was performed on an ABI automated sequencer. Chromato- 
graphs were checked by eye to ensure the accuracy of the final sequences and ambiguous nucleotides denoted with an ' $n$ '. Both strands of the DNA region were sequenced, and sequencing was repeated where necessary. Sequences were submitted to GenBank (accession numbers, D2 region: AY190190-AY190224, ITS region: AY190225-AY190239).

Phylogenetic analysis. Sequences were aligned with ClustalX (Thompson et al. 1997) using unrestricted data. Sequence alignments were checked by eye, and alignment parameters adjusted where necessary to improve the alignment. Phylogenetic analysis of sequences was performed with maximum likelihood using PAUP 4.0 beta 10 (Swofford 2002). A SYM-model (general time-reversible model with equal base frequencies) was used, and branch lengths were calculated. The analysis was performed with a heuristic strategy using likelihood as the criterion. MrBayes (Huelsenbeck \& Ronquist 2001) was also used to analyze the data, with a burn-in value of 50000 generations out of 500000 generations. A general time reversible model was used, with gamma-distributed rate variation. Trees were drawn with TreeView.

Scanning electron microscopy (SEM). Spicules were prepared for SEM by dissolving sponge tissue in concentrated nitric acid. Spicules were then washed twice in distilled water and twice in absolute alcohol. Cleaned spicules in $70 \%$ ethanol were spread on cover-slips attached to SEM stubs, dried at $70^{\circ} \mathrm{C}$ overnight, then sputter-coated with gold prior to examination with a Philips SEM 505 operating at $15 \mathrm{kV}$. Suitable images were recorded electronically.

Spicule dimensions. The diameters of spicules cleaned with nitric acid were measured using light microscopy. Twenty-five oxysphaerasters and 25 oxyasters were measured (where both types were present) from the type specimen of Chondrilla australiensis, and from 1 individual of each of the other 2 Chondrilla species found in Australian waters.

\section{RESULTS}

Phylogenetic trees produced by PAUP and MrBayes had the same branching patterns, and only trees made by MrBayes have been presented here, with the confidence levels at branching points. Sequence analysis of both the D2 region of the 28S rDNA and the ITS15.8S-ITS2 regions revealed 4 distinct genetic clusters within the Chondrilla specimens; 3 from Australia and 1, C. nucula, from the Mediterranean and Ligurian Seas. One more specimen, from Bermuda, was sequenced using the C2 D2 primer pair (Fig. 2) and found to cluster separately. The phylogenetic clusters agreed with consistent morphological and spicule dif- ferences found between these specimens (see below), and it can therefore be concluded that they represent 5 taxa: C. australiensis, $C$. nucula and 3 unidentified Chondrilla species, designated species 2, 3 and 4. In southern Western Australia specimens of 3 species of Chondrilla (C. australiensis, Chondrilla sp. 2 and 3) sometimes occurred sympatrically (Fig. 1).

The 2 primer sets gave very similar results in terms of sequence similarities and in the resulting phylogenetic trees (Figs. $2 \& 3$ ). Both phylogenetic trees showed Chondrilla nucula from the Mediterranean clustering most closely to Chondrilla sp. 3 from southern Australia, and Chondrilla sp. 2 from southern Australia was the most distant from $C$. australiensis, which also occurs in southern Australia (Figs. 2 \& 3). C. australiensis was found in almost every Australian state (Fig. 1), suggesting that Chondrilla species can be extensively distributed around a continuous coastline.

\section{Sequence analysis : C2 D2 region}

Chondrilla nucula (Mediterranean), Chondrilla sp. 3 (southern Australia) and Chondrilla sp. 4 (Bermuda) are from widely separated geographic regions, but cluster closely on the basis of both the phylogenetic analysis of the D2 region and spicule similarities (see below). Sequence similarities between D2 sequences of C. australiensis range from $99.1 \%$ (4 base pair difference) to $100 \%$, with most sequences only being 1 or 2 base pairs different to each other. The exception was the sample from Dampier, which typically had $97.5 \%$ sequence similarity to other samples of C. australiensis. Chondrilla sp. 2 samples had 98.4 to $99.8 \%$ sequence similarity to each other. Chondrilla sp. 3 samples from Western Australia were 100\% similar to each other and $99.3 \%$ similar to those from South Australia. With this region of DNA, South Australian samples of Chondrilla sp. 3 showed slightly separate clustering from the southern Western Australian samples (Fig. 2). C. nucula from Marseille and Portofino had $100 \%$ sequence similarity. Between species sequence similarities ranged from a low of $85.5 \%$ between the type of $C$. australiensis and Chondrilla sp. 2 , to the highest similarity of $92.9 \%$ between Chondrilla sp. 4 (Bermuda) and Chondrilla sp. 3. The D2 region contained 113 parsimony informative sites.

\section{Sequence analysis : ITS15.8S-ITS2 region}

The branching pattern of the phylogenetic tree produced with the ITS region (Fig. 3) was the same as that for the D2 region. Sequence similarities between Chondrilla australiensis samples ranged from 96.6 to 


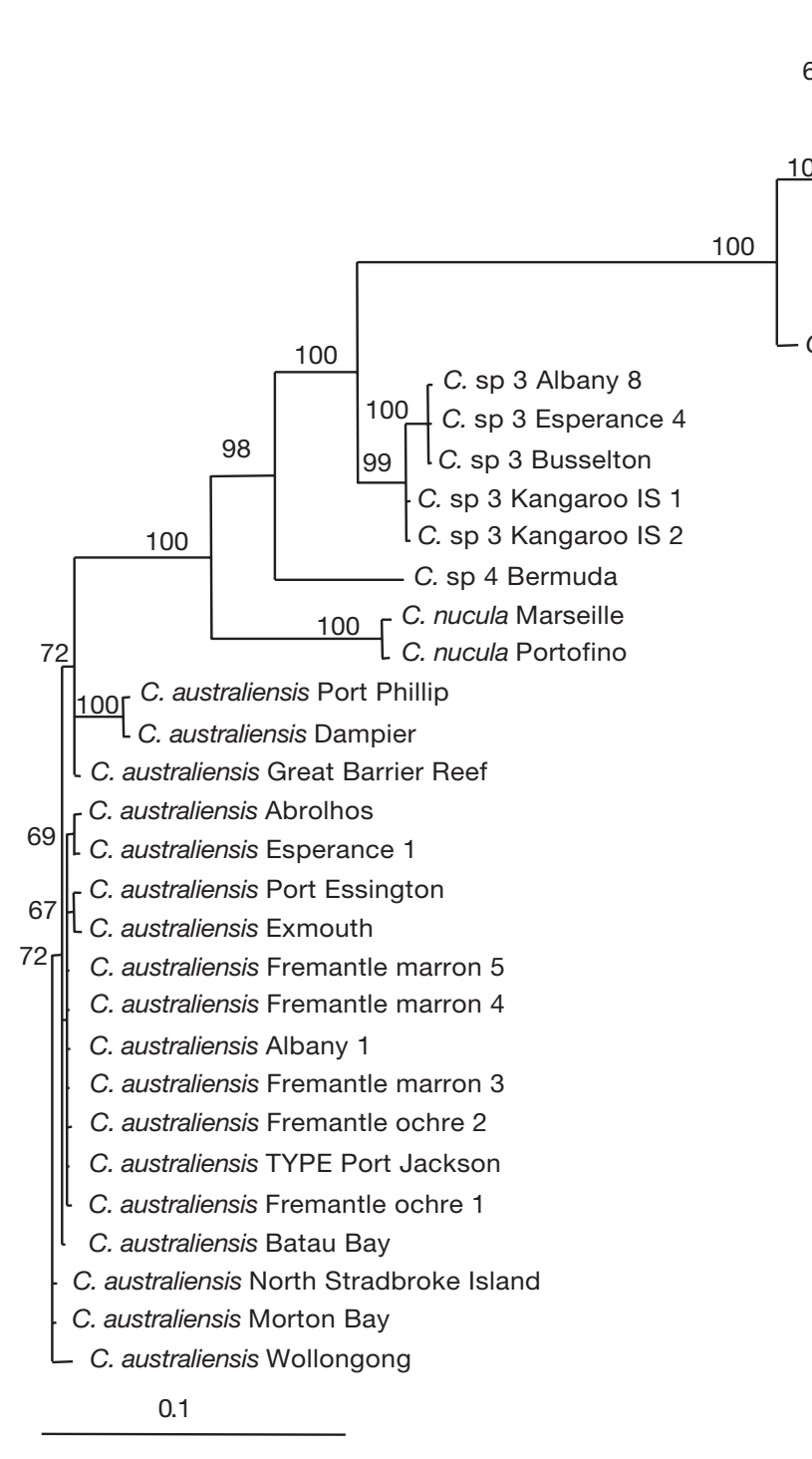

$100 \%$, and for both Chondrilla sp. 2 and 3 similarities between individuals of the same species ranged from 99.7 to $100 \%$. Sequences of Chondrilla sp. 3 from Western Australia were only 2 base pairs different to samples from South Australia. Between species sequence similarities were very similar to those obtained with the D2 region, with the lowest being $86.1 \%$ between C. australiensis and Chondrilla sp. 2, and the highest being $92.9 \%$ between $C$. nucula and Chondrilla sp. 3. Chondrilla sp. 4 was not amplified with these primers. The ITS1-5.8S-ITS2 region contained 100 parsimony informative sites.

\section{Spicule and morphological differences}

All Chondrilla species in this study were encrusting, but with field-collecting experience, Australian Chon-
Fig. 2. Phylogenetic tree produced with MrBayes, using the D2 region of the 28S rDNA. Confidence levels are given at nodes. $C$. australiensis $=$ Chondrilla australiensis, $C$. sp $2=$ Chondrilla sp. 2, C. sp $3=$ Chondrilla sp. 3, C. sp $4=$ Chondrilla sp. 4 . Scale bar $=0.1$ substitutions per site. See Table 1 for sample IDs

drilla species could be distinguished from each other in $s i t u$, based on differences in colour, thickness and resilience (Table 2). C. nucula from the Mediterranean was also morphologically distinct. C. nucula and Chondrilla sp. 3 and 4 had only 1 type of aster, the oxysphaeraster. While the oxysphaerasters of these species were similar in appearance, each contained a distinct size class, with those from Chondrilla sp. 3 being the smallest and those from C. nucula the largest (see below). This similarity in spicule complement is reflected in the phylogenetic clustering of these 3 species (Fig. 2).

Chondrilla sp. 2 was found in southern Western Australia, South Australia and Victoria (Fig. 1). The species was observed only on heavily shaded rock faces at depths of less than $15 \mathrm{~m}$. This species grew in continuous sheets that were relatively stiff to touch compared to other Chondrilla species. Very large individuals (typical of C. australiensis) were not observed. Chondrilla sp. 2 had 2 size classes of oxysphaerasters (Table 2) and no oxyasters (Fig. 4A).

Chondrilla australiensis was found in every state of Australia except South Australia, where sampling was very limited, and Tasmania (Fig. 1), where sampling was not undertaken. This distribution includes tropical and temperate waters. The species was very abundant and occurred on vertical and horizontal rock faces at depths of 1 to $25 \mathrm{~m}$. The colour was variable, ranging from a reddish brown to yellow/brown, depending on the light intensity of the environment. Thickness also varied (Table 2) and was possibly related to the health status of the individual. C. australiensis had both oxysphaerasters and oxyasters (Fig. 4B), with the rays of the latter sometimes bent and divided at the ends. The spicules of the type specimen of $C$. secunda were consistent with this description.

Chondrilla sp. 3 was found in southern Western Australia, South Australia and Tasmania (Fig. 1). The species occurred only on heavily shaded rock faces, under jetties and in caves at depths less than $15 \mathrm{~m}$. Individuals were typically thicker than $C$. australiensis and Chondrilla sp. 2 (Table 2), and much smaller (approximately 5 or $6 \mathrm{~cm}^{2}$ ), were soft to touch, and had a distinct 'skin' that was easy to detach. Chondrilla sp. 3 
Fig. 3. Phylogenetic tree produced with MrBayes, using ITS1-5.8S-ITS2 region. Details as for Fig. 2



had 1 aster type only, a small oxysphaeraster (Fig. 4C). A Tasmanian specimen from the NHM (BMNH 25.11.1.1331) previously named $C$. nucula, had spicules consistent with Chondrilla sp. 3.

Chondrilla nucula was found in the Mediterranean Sea, France, and the Ligurian Sea, Italy. The species was abundant in areas where it occurred, and it was growing on rock and the base of seagrass at depths of $1 \mathrm{~m}$ or more. Specimens were dark brown and approximately $5 \mathrm{~mm}$ thick. Individuals were very small, typically 1 to $3 \mathrm{~cm}$ long and 0.5 to $1 \mathrm{~cm}$ wide. The spicules are oxysphaerasters 25 to $30 \mu \mathrm{m}$ in diameter.

Chondrilla sp. 4 was provided preserved in ethanol by the NHM (BMNH 1948.8.6.55) and had been named $C$. nucula. As it was not observed in situ, a description of the species and growth habits cannot be provided. The species has oxysphaerasters approximately $20 \mu \mathrm{m}$ in diameter.

\section{DISCUSSION}

The molecular and classical analyses undertaken for the species of Chondrilla from Australia, the Mediterranean and Bermuda suggest that Chondrilla species are not cosmopolitan in their distribution, although they may be extensively distributed along a continuous coastline. In addition, evidence was found

0.1

Table 2. Spicule and morphological differences between the Australian Chondrilla species

\begin{tabular}{|c|c|c|c|c|}
\hline & Chondrilla australiensis & \multicolumn{2}{|c|}{ Chondrilla sp. 2} & Chondrilla sp. 3 \\
\hline Colour & Reddish/brown to yellow/brown & \multicolumn{2}{|c|}{ Dark to pale brown } & $\begin{array}{l}\text { Dark brown, sometimes } \\
\text { with cream flecks }\end{array}$ \\
\hline Approx. thickness & $\begin{array}{l}\text { Variable: } 1 \mathrm{~mm} \text { to }>5 \mathrm{~cm} \text {, } \\
\text { usually about } 1 \mathrm{~cm}\end{array}$ & \multicolumn{2}{|l|}{1 to $2 \mathrm{~cm}$} & 3 to $5 \mathrm{~cm}$ \\
\hline Abundance & Abundant & \multicolumn{2}{|c|}{ Common at some locations } & Usually rare \\
\hline Size & $\begin{array}{l}\text { Usually about } 50 \mathrm{~cm}^{2} \text {, can be } \\
\text { up to } 1 \mathrm{~m}^{2}\end{array}$ & \multicolumn{2}{|c|}{ Usually about $30 \mathrm{~cm}^{2}$} & $\begin{array}{l}\text { Usually about } 5 \mathrm{~cm}^{2} \text {, } \\
\text { occasionally larger }\end{array}$ \\
\hline Resilience & Rubbery & \multicolumn{2}{|l|}{ Stiff } & Very soft \\
\hline Matrix colour & Cream & \multicolumn{2}{|c|}{ Cream/brown } & Dark brown \\
\hline $\begin{array}{l}\text { Oxyasters } \\
\text { Size range }(\mu \mathrm{m}) \\
\text { Average size }(\mu \mathrm{m}) \\
\mathrm{SD}(\mathrm{n}=25)\end{array}$ & $\begin{array}{l}\text { Yes } \\
18.8 \text { to } 25 \\
21.9 \\
1.8\end{array}$ & \multicolumn{2}{|l|}{ No } & No \\
\hline Oxysphaerasters & Yes & \multicolumn{2}{|l|}{ Yes } & Yes \\
\hline Oxysphaeraster & & Small & Large & \\
\hline Size range $(\mu \mathrm{m})$ & 22.5 to 28.8 & 12.5 to 27.5 & 45 to 90 & 10 to 17.5 \\
\hline Average size $(\mu \mathrm{m})$ & 25.6 & 20 & 75.4 & 14.4 \\
\hline $\mathrm{SD}(\mathrm{n}=25)$ & 2.1 & 4 & 12.5 & 2.5 \\
\hline
\end{tabular}


for the occurrence of 3 Chondrilla species in Australian waters. These coexist in some areas, and 2 appear to be previously unreported species. This provides new insights into the biogeography of this genus in Australia and the dispersal abilities of oviparous sponges.
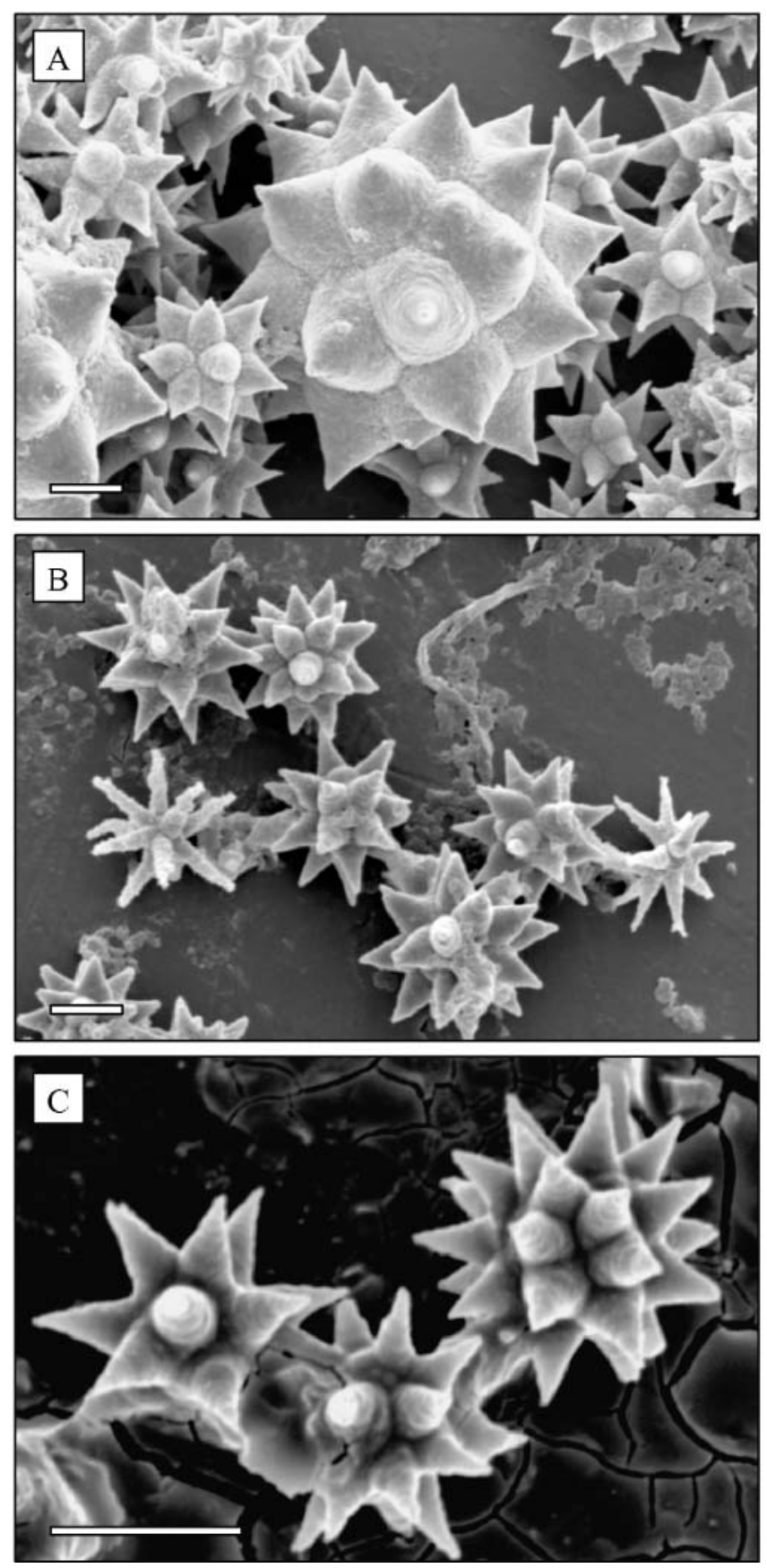

Fig. 4. Scanning electron microscope (SEM) images of the spicules of the Australian Chondrilla species. Scale bars = $10 \mu \mathrm{m}$. (A) Oxysphaerasters of Chondrilla sp. 2. (B) Oxysphaerasters and oxyasters of Chondrilla australiensis. (C) Oxysphaerasters of Chondrilla sp. 3
Three species of Chondrilla had been reported to occur around the Australian mainland - C. australiensis, C. nucula and C. secunda-but there had been no studies of their distribution in Australian waters. The type specimens of C. australiensis and C. secunda were from New South Wales and Victoria, respectively, and specimens named C. australiensis had been collected from Shark Bay, Western Australia, and Victoria. C. nucula had previously been reported to occur in Tasmania.

This study provides evidence for the presence of 3 species of Chondrilla around Australia, but only one of these, C. australiensis, coincided with previous records of Chondrilla species in this region. The other 2 species, designated Chondrilla sp. 2 and 3, appear to be new species, but analysis of type material from other countries will be necessary to establish whether this is the case. These species will be formally described in a future publication. There was no evidence found for the presence of C. nucula in Australia, and $C$. secunda appears to be a synonym of $C$. australiensis; however, the type specimen of the latter was not successfully sequenced. Material of C. mixta was not examined, and this species was not found during sampling undertaken in this study.

Chondrilla australiensis, Chondrilla sp. 2 and 3 were differentiated by sequences from the D2 region of the 28s rDNA and ITS1-5.8S-ITS2 region and consistent differences in gross morphology, spicule complement, size and shape. Comparison of the 2 DNA regions showed that the greatest genetic distance occurred between Chondrilla sp. 2 and C. australiensis (85.5 and $86.1 \%$ sequence similarity for D2 and ITS regions, respectively). The sequence similarity between $C$. australiensis and C. nucula was 91 and $88.7 \%$ for the D2 region and ITS regions, respectively. It is interesting that $C$. australiensis and $C$. nucula have less genetic distance between them than between $C$. australiensis and Chondrilla sp. 2, when there is a large geographical distance between the former species pair and a sometimes sympatric distribution in the latter pair. $C$. nucula from the Mediterranean is most closely related to Chondrilla sp. 3 from southern Australia and Chondrilla sp. 4 from Bermuda, and these 3 species form a cluster in both the D2 phylogenetic analysis and spicule complement (all 3 species have oxysphaerasters only).

Based on spicule analysis, the NHM sample from Tasmania named Chondrilla nucula belongs to Chondrilla sp. 3, a closely related but distinct species. C. nucula was not found in Australia, and it can be concluded that it is unlikely to occur in this country. The type specimen of $C$. nucula is from the Adriatic Sea, and it was collected in France and Italy for this study. The finding that $C$. nucula from the Mediterranean Sea and the 
Ligurian Sea are the same species, based on DNA sequencing and classical techniques, is in agreement with allozyme analysis of these populations (Klautau et al. 1999) and shows that this species also has a large range along continuous coastline. However, the results of this study and that by Klautau et al. (1999) indicate that reports of this species in countries distant to the Mediterranean region should be treated with caution until more extensive analyses are conducted.

Chondrilla australiensis, Chondrilla sp. 2 and 3 all have very large geographical distributions in Australia (Fig. 1). The probable Australia-wide distribution of $C$. australiensis is surprising, given the tropical to temperate temperature range around the Australian coastline and the supposed limited dispersal ability of sponge larvae. C. australiensis was found in all Australian states with the exception of South Australia and Tasmania. However, sampling in these 2 states was not possible for this study, or was very limited, so the presence or absence of $C$. australiensis in these regions cannot be confirmed. Chondrilla sp. 2 and 3 appear to be restricted to the cool southerly regions of Australia (Fig. 1).

There have been no studies on the larvae of Chondrilla species, and data on the larvae of any oviparous sponge species are extremely rare. The free-swimming larval stages of oviparous sponges are thought to be short-lived (Lévi \& Lévi 1976) and therefore their dispersal abilities are considered to be low (Watanabe \& Masuda 1990, Lazoski et al. 2001). However, caution is necessary when making assumptions on the dispersal ability of larvae based on knowledge from other sponge species with an apparently similar mode of reproduction. For example, Uriz et al. (1998) found that the behaviour of the larvae of 2 species of viviparous sponges, Scopalina lophyropoda and Crambe crambe, greatly affected their dispersal ability. Ayre (1990) stated that severely restricted larval dispersal is common for marine invertebrates which have extensive geographic ranges and cautioned that there are difficulties with using observational data of larvae to infer dispersal distances.

Two studies using allozyme analysis have found very large geographic distributions for oviparous sponges: Klautau et al. (1999) found a species of Chondrilla along $3000 \mathrm{~km}$ of coastline in Brazil, and Lazoski et al. (2001) found 1 species of the related genus Chondrosia along more than $8000 \mathrm{~km}$ in the West Atlantic, demonstrating that geographically widely separated populations are capable of some gene flow. It is possible that the presence of symbiotic cyanobacteria in the eggs of C. australiensis (Usher et al. 2001) may increase the survival time and dispersal ability of both the eggs and larvae of this sponge in the water column by providing photosynthates, as suggested for the larvae of corals that contain algae (Richmond 1990).
In Western Australia the Leeuwin current, which typically runs in autumn and winter, carries the larvae of marine invertebrates from the north of the state southward along the Western Australian coast, then eastward into the Great Australian Bight (Maxwell \& Cresswell 1981). However, during the summer period the northerly flowing West Australian Current can predominate along the west coast of Australia (Rochford 1969), and it may reverse the direction of larval transport from the south to the north of Western Australia. Furthermore, genetic studies of 3 species of marine invertebrates with a pelagic larval phase suggest that populations separated by thousands of kilometers are genetically connected by the southern Australian currents (Ayre 1990). This current may also explain the distribution of Chondrilla sp. 2 and 3 along the southwest and southern coast of Australia. In eastern Australia the East Australian Current (Hamon et al. 1975) makes the transport of larvae southwards likely. However, larval dispersal of marine invertebrates around the northern coast of Australia is less studied. The Equatorial Current sweeps westwards between 11 and $14^{\circ} \mathrm{S}$ throughout the year (Rochford 1969), potentially connecting western and eastern populations in the north of Australia, and some larvae may be carried from the north of Western Australia to the south by the Leeuwin Current.

The phenomenon of rafting may also be an important means of long-distance dispersal for clonal species of benthic marine invertebrates (Jackson 1986), and studies show that gene flow among populations will be distorted by the effect of asexual reproduction (Sarà et al. 1989, Ayre 1990). Asexual reproduction is believed to have an important role in maintaining populations of some sponge species (Wulff 1985, 1991, Corriero et al. 1998, Solé-Cava \& Boury-Esnault 1999), and it has the potential to rapidly disperse genotypes throughout a continuous reef system (Wulff 1985). However, the relative contributions of sexual and asexual reproduction to sponge populations are still not well known (SoléCava \& Thorpe 1994).

Individuals of Chondrilla australiensis were observed fragmenting hand-sized pieces during the late austral summer period, when they are developing gametes (Usher et al. 2001), and eggs have been found in drifting fragments of both C. australiensis and Chondrilla sp. 2 (K. M. Usher \& J. Fromont pers. obs.). The life expectancy of a drifting sponge fragment may not be limited by a need to rapidly settle on the substrate, and it is possible that healthy fragments of Chondrilla are carried by currents for very long periods of time. Fragments containing developing gametes may release mature gametes after having travelled some distance, thereby facilitating the interbreeding of distant populations. Maldonado \& Uriz (1999) observed 
this process in the brooding sponge Scopalina lophyropoda, which released viable larvae up to $28 \mathrm{~d}$ after fragmenting. C. nucula is also known to use fragmentation to disperse (Gaino \& Pronzato 1983). The degree to which Chondrilla sp. 2 fragments is not known, and Chondrilla sp. 3 has not been observed as free pieces or in the process of fragmenting to date. However observations of this possibly new species are very limited.

In conclusion, 3 Chondrilla species in Australia are distributed over thousands of kilometers. It appears that the larvae and/or fragments of Chondrilla are able to disperse across very large distances around the coastline of Australia. The lack of knowledge of the way in which populations are structured, the contributions of sexual versus asexual reproduction, and the life history and behavior of the larvae of Chondrilla species severely limits our understanding of population structure of this genus. Sequencing of both the D2 and ITS1 and ITS2 regions and spicule characteristics are useful for distinguishing closely-related Chondrilla species.

Acknowledgements. We would like to thank the following people for kindly providing samples of Chondrilla specimens: C. Valentine from the Natural History Museum, London, Dr. B. Alvarez, Museum and Art Gallery of the Northern Territory, S. Cook, Queensland Museum, Dr. A. Davis, University of Wollongong, NSW, M. Milanese, University of Genoa, and M. Sidri, University of Stuttgart. We would also like to thank Prof. J. Vacelet, Centre d'Océanologie de Marseille, for assistance in collecting and identifying sponge samples from the Mediterranean Sea. Bioinformatics analyses conducted on BioNavigator.com was provided by the Entigen Corporation. This study was supported by a grant from the Australian Biological Resources Study.

\section{LITERATURE CITED}

Ayre DJ (1990) Population subdivision in Australian temperate marine invertebrates: larval connections versus historical events. Aust J Ecol 15:403-411

Baroin A, Perasso R, Qu LH, Brugerolle G, Bachellerie JP, Adoutte A (1988) Partial phylogeny of the unicellular eukaryotes based on rapid sequencing of a portion of $28 \mathrm{~S}$ ribosomal RNA. Proc Natl Acad Sci USA 85:3474-3478

Bavestrello G, Bonito M, Sarà M (1993) Silica content and spicular size variation during an annual cycle in Chondrilla nucula Schmidt (Porifera, Demospongiae) in the Ligurian Sea. Sci Mar 57:421-425

Borchiellini C, Chombard C, Lafay B, Boury-Esnault N (2000) Molecular systematics of sponges (Porifera). Hydrobiologia 420:15-27

Boyce E (1999) Systematics of Tethya (Porifera, Demospongiae, Hadromerida) in the Perth region. Honors thesis, Murdoch University, Western Australia

Chombard C, Boury-Esnault N, Tillier S (1998) Reassessment of homology of morphological characters in Tetractinellid sponges based on molecular data. Syst Biol 47:351-366

Corriero G, Scalera Liaci L, Nonnis Marzano C, Gaino E (1998) Reproductive strategies of Mycale contarenii
(Porifera: Demospongiae). Mar Biol 131:319-327

Gaino E, Pronzato R (1983) Étude en microscopie électronique du filament des formes étirées chez Chondrilla nucula Schmidt (Porifera, Demospongiae). Ann Sci Nat Zool Biol Anim 5:221-234

Hamon BV, Godfrey JS, Greig MA (1975) Relation between mean sea level, current and wind stress on the east coast of Australia. Aust J Mar Freshw Res 26:389-403

Hassouna N, Michot B, Bachellerie JP (1984) The complete nucleotide sequence of mouse 28S rRNA gene. Implications for the process of size increase of the large subunit rRNA in higher eukaryotes. Nucleic Acids Res 12: 3563-3583

Hooper JNA, Wiedenmayer F (1994) Chondrillidae. In: Wells A, Hooper JNA, Wiedenmayer F (eds) Zoological catalogue of Australia, Vol 12. Porifera. Australian Biological Resources Study, CSIRO Publishing, Collingwood, Victoria, p 122-125

Hooper JNA, Capon RJ, Keenan CP, Parry DL (1991) Morphometric and biochemical differences between sympatric populations of the Clathria spicata species complex (Demospongiae: Poeciloscerida: Microcionidae) from northern Australia. In: Reitner J, Keupp H (eds) Fossil and recent sponges. Springer-Verlag, Berlin, p 271-288

Huelsenbeck JP, Ronquist FR (2001) MrBayes: Bayesian inference of phylogeny. Biometrics 17:754-755

Jackson JBC (1986) Modes of dispersal of clonal benthic invertebrates: consequences for species distributions and genetic structure of local populations. Bull Mar Sci 39: 588-606

Jones WC (1984) Spicule dimensions as taxonomic criteria in the identification of sponges from the shores of Anglesey. Zool J Linn Soc 80:239-259

Klautau M, Russo CAM, Lazoski C, Boury-Esnault N, Thorpe JP, Solé-Cava AM (1999) Does cosmopolitanism result from overconservative systematics? A case study using the marine sponge Chondrilla nucula. Evolution 53: 1414-1422

Lazoski C, Solé-Cava AM, Boury-Esnault N, Klautau M, Russo CAM (2001) Cryptic speciation in a high gene flow scenario in the oviparous marine sponge Chondrosia reniformis. Mar Biol 139:421-429

Lévi C (1979) Remarques sur la taxonomie des démosponges. Coll Int Cent Natn Rech Scient 291:487-502

Lévi C, Lévi P (1976) Embryogenèse de Chondrosia reniformis (Nardo), Démosponge ovipare, et transmission des bactéries symbiontiques. Ann Sci Nat Zool Biol Anim 18: 367-380

Maldonado M, Uriz MJ (1999) Sexual propagation by sponge fragments. Nature 398:476

Maxwell JGH, Cresswell GR (1981) Dispersal of tropical marine fauna to the Great Australian Bight by the Leeuwin current. Aust J Mar Freshw Res 32:493-500

McInerney JO, Adams CL, Kelly M (1999) Phylogenetic resolution potential of $18 \mathrm{~S}$ and 28S rRNA genes within the Lithistid Astrophorida. In: Hooper JNA (ed) Proc 5th Int Sponge Symp 1998. Mem Queensl Mus 44:343-351

Muricy G, Solé-Cava AM, Thorpe JP, Boury-Esnault N (1996) Genetic evidence for extensive cryptic speciation in the subtidal sponge Plakina trilopha (Porifera: Demospongiae: Homoscleromorpha) from the Western Mediterranean. Mar Ecol Prog Ser 138:181-187

Richmond RH (1990) Relationships among reproductive mode, biogeographic distribution patterns and evolution in Scleractinian corals. In: Hoshi M, Yamashita O (eds) Advances in invertebrate reproduction, Vol 5. Elsevier, Amsterdam, p 317-322 
Rochford DJ (1969) Seasonal variations in the Indian Ocean along $110^{\circ} \mathrm{E}$. 1. Hydrological structure of the upper $500 \mathrm{~m}$. Aust J Mar Freshw Res 20:1-50

Sarà M, Mensi P, Manconi R, Bavestrello G, Balletto E (1989) Genetic variability in Mediterrenean populations of Tethya (Porifera: Demospongiae). In: Ryland JS, Tyler PA (eds) Reproduction, genetics and distributions of marine organisms. Olsen \& Olsen, Fredensborg, p 293-298

Sarà M, Corriero G, Bavestrello G (1993) Tethya (Porifera, Demospongiae) species coexisting in a Maldivian coral reef lagoon: taxonomical, genetic and ecological data. Mar Ecol 14:341-355

Solé-Cava AM, Boury-Esnault N (1999) Patterns of intra and interspecific genetic divergence in marine sponges. In: Hooper JNA (ed) Proc 5th Int Sponge Symp 1998. Mem Queensl Mus 44:591-601

Solé-Cava AM, Thorpe JP (1986) Genetic differences between morphotypes of the marine sponge Suberites ficus (Demospongiae: Hadromerida). Mar Biol 93:247-253

Solé-Cava AM, Thorpe JP (1994) Evolutionary genetics of marine sponges. In: van Soest RWM, van Kempen TMG, Braekman JC (eds) Sponges in time and space. AA Balkema, Rotterdam, p 55-63

Solé-Cava AM, Boury-Esnault N, Vacelet J, Thorpe JP (1992) Biochemical genetic divergence and systematics in sponges of the genera Corticum and Oscarella (Demospongiae: Homoscleromorpha) in the Mediterranean Sea. Mar Biol 113:299-304

Swofford DL (2002) PAUP* Phylogenetic Analysis Using Parsimony ( ${ }^{*}$ and other methods), Ver 4. Sinauer Associates, Sunderland, MA

Thompson JD, Gibson TJ, Plewniak F, Jeanmougin F, Higgins DG (1997) The ClustalX windows interface: flexible strategies for multiple sequence alignment aided by quality analysis tools. Nucleic Acids Res 24:4876-4882

Uriz MJ, Maldonado M, Turon X, Marti R (1998) How do reproductive output, larval behaviour, and recruitment contribute to adult spatial patterns in Mediterranean encrusting sponges? Mar Ecol Prog Ser 167:137-148

Editorial responsibility: Otto Kinne (Editor),

Oldendorf/Luhe, Germany
Usher KM, Kuo J, Fromont J, Sutton D (2001) Vertical transmission of cyanobacterial symbionts in the marine sponge Chondrilla australiensis (Demospongiae). Hydrobiologia 461:15-23

van Oppen MJH, Wöerheide G, Takabayashi M (2002) Nuclear markers in evolutionary and population genetic studies of scleractinian corals and sponges. Proc 9th Int Coral Reef Symp Bali, Indonesian Institute of Sciences, Jakarta

Wang PH, White JG (1997) Molecular characterization of Pythium species based on RFLP analysis of the internal transcribed spacer region of ribosomal DNA. Physiol Mol Plant Path 51:129-143

Watanabe Y, Masuda Y (1990) Structure of fibre bundles in the egg of Tetilla japonica and their possible function in development. In: Rützler K (ed) New perspectives in sponge biology. Smithsonian Institute Press, Washington, DC, p 193-199

Wörheide G (1998) The reef cave dwelling ultraconservative coralline Demosponge Astrosclera willeyana Lister 1900 from the Indo-Pacific. Morphology, ultrastructure, biocalcification, isotope record, taxonomy, biogeography, phylogeny. FACIES 38:1-88

Wörheide G, Degnan BM, Hooper JNA (2000) Population phylogenies of the common Coral reef sponges Leucetta spp. and Pericharax spp. (Porifera: Calcarea) from the Great Barrier Reef and Vanuatu. Proc 9th Int Coral Reef Symp Abstracts, Indonesian Institute of Sciences, Jakarta, p 23

Wörheide G, Hooper JNA, Degnan BN (2002) Phylogeography of western Pacific Leucetta 'Chagosensis' (Porifera: Calcarea) from ribosomal DNA sequences: implications for population history and conservation of the Great Barrier Reef World Heritage Area (Australia). Mol Ecol 11:1753-1768

Wulff JL (1985) Dispersal and survival of fragments of coral reef sponges. Proc 5th Int Coral Reef Congr 5:119-124

Wulff JL (1991) Asexual fragmentation, genotype success, and population dynamics of erect branching sponges. J Exp Mar Biol Ecol 149:227-247

Submitted: March 26, 2003; Accepted: November 25, 2003 Proofs received from author(s): March 31, 2004 
